\title{
STRETCHING THE BOUNDARIES: USING ALN TO REACH ON-CAMPUS STUDENTS DURING AN OFF-CAMPUS SUMMER SESSION
}

X. Christine Wang

xcwang@ncsa.uiuc.edu

Alaina Kanfer

alaina@ncsa.uiuc.edu

D. Michelle Hinn

dmhinn@ncsa.uiuc.edu

Technology Research Group

National Center for Supercomputing Applications (NCSA)

University of Illinois at Urbana-Champaign (UIUC)

http://www.ncsa.uiuc.edu/edu/trg

Tel: 217/244-1070

Fax: 217/265- 8022

Lanny Arvan

1-arvan@ntx1.cso.uiuc.edu

College of Commerce \& Business Administration, UIUC

http://www.cba.uiuc.edu/ 1-arvan//

\begin{abstract}
In this article we study an innovative use of asynchronous learning networks (ALN) to stretch the boundaries of the traditional university campus.

An ALN was used to allow traditional on-campus students to take a required course, ECON 300: Intermediate Microeconomic Theory, during summer session while they were off campus, working summer jobs at home. Pre- and post surveys consisting of open-ended and rating scale questions were administered to 29 students. The surveys were used to assess the degree of student satisfaction with various aspects of the online learning experience and their learning environments at home as well as to assess additional important characteristics for successful online learning such as motivation, selfdiscipline and time management.

The results indicate that the transfer from the traditional face-to-face classroom during the academic year to the online summer session requires strong motivation, self-discipline, good time management skills, and a comfortable learning environment including a stable Internet connection. The students' learning outcomes were closely related to their satisfaction with online communication, technical support, and the course design. Furthermore, prior online class experience affected learning outcomes. Additionally, prior experience with the technologies and a positive attitude toward technology were found to be important for successful online learning.

The importance of online course design and student preparation, particularly when traditional on-campus students attend a summer school course through ALN, is discussed.
\end{abstract}

KEYWORDS ALN, summer school, traditional on-campus undergraduates, online learners 


\section{INTRODUCTION}

The Asynchronous Learning Networks (ALN) model carries the promise of overcoming barriers of physical isolation, distance and those imposed by rigid time constraints [1], as well as the capability of producing efficiency gains in courses without decreases in the quality of instruction and learning [2][3]. The ALN model is one of the most common online instruction and learning models. As defined on the ALN Web site (http://www.aln.org):

ALN(s) are people networks for anytime and anywhere learning. ALN combines self-study with substantial, rapid, asynchronous interactivity with others. In ALN, learners use computer and communications technologies to work with remote learning resources, including instructors and other learners, but without the requirement to be online at the same time.

ALNs are useful in many educational arenas, but have been used primarily for off-campus education, continuing education and corporate training [3]. Some schools even use ALNs to offer degree programs. For example, the New Jersey Institute of Technology offers the B.A. in Information Systems and the B.S. in Computer Science via an ALN system called the Virtual Classroom [4]. Another example is the campuses of the State University of New York (SUNY) that offer complete degree programs through an ALN (for more information, see SUNY Learning Network at http://sln.suny.edu/admin/sln/original.nsf). Corporate training professionals also propose using ALNs as a valuable and efficient way to enhance the computer literacy of their employees [5].

In addition to the more traditional implementations of ALNs in distance education, there are also applications of ALNs in on-campus education. Frequently, ALNs are used in on-campus settings as a means for managing large classes by enhancing learning opportunities, reducing costs, and providing outreach [2][6][7]. For instance, Bourne [3] describes how an ALN is integrated into a large on-campus engineering science course (ES130) to enhance learning at Vanderbilt University. In addition, ALNs have been used in hybrid on-campus/distance models in cases where students in a class on one campus might benefit from regular interactions with a class on a different campus. An example of this hybrid model is the urban design course offered simultaneously at the University of Illinois at UrbanaChampaign (UIUC) and the University of Illinois at Chicago, described by Al-Kodmany, George, Marks, and Skach [8].

The boundaries for implementing ALNs are being extended with the broad public availability of new technologies and the emergence of the research findings of the existing implementations.

In addition to universities incorporating elements of ALNs into their traditional classrooms, many companies are adopting self-paced ALNs for employee training instead of traditional instructor-led classroom training events. However, it is not known how well learners who are used to traditional face-toface learning environments and who do not necessarily prefer ALNs adapt when placed in a situation that requires learning via an ALN. In order to address this we examined a situation where university students from a traditional face-to-face classroom environment took a class in an ALN. During the 1999 summer school session, the Department of Economics at UIUC tried a new way of applying ALN in higher education. Rather than the typical ALN offering in which self-selected students who prefer ALN enroll, in this case the College of Commerce and Business Administration used an ALN system to offer a course (ECON 300: Intermediate Microeconomic Theory) to their full-time traditional undergraduate students who were home for the summer.

During summer sessions, many undergraduate students work at jobs away from campus because of increased job market opportunities or to be closer to their families. Usually these students either take courses from a local community college or simply take the summer off from classes. When students take courses from local community colleges, although universities do accept transfer credit, there is a concern about the comparability of those transfer credits and those offered by the universities. More specifically, there are concerns about whether pre-requisite requirements fulfilled externally leave students at a disadvantage in the subsequent course taken at their home universities. On the other hand, when students take the summer off because of summer jobs, this may delay their finishing college. Both transferring 
credits from community colleges and the delay of finishing college because of summer jobs concern higher educators. The innovation of offering courses to on-campus students while they are home for the summer through an ALN system potentially provides a good solution to these concerns. In this way, the students are able to take a qualified class from the university that fulfills their course requirements while they are simultaneously working at a summer job away from campus.

In this article, we examine this pilot implementation of an ALN to teach a summer school course to traditional on-campus students who were away from campus during summer session. Specifically, we are interested in the students' reaction to moving from a traditional classroom setting to the ALN environment where they were separated from their peers, as well as working at summer jobs. In the following section, we describe the backgrounds of the students, the teaching staff, the course structure, and the technologies used in this course. Then we examine the relevant literature in this field and present our research agenda. Next, we present the survey methodology with an analysis of the results of the surveys. We conclude with a discussion of the implications of our findings for future research and implementations of ALNs for people who are used to traditional learning environments.

\section{BACKGROUND}

ECON 300: Intermediate Microeconomic Theory is a core course required of business majors as well as a course that fulfills the social science requirement for non-majors and is offered every semester including summer semesters. In the past, it was only offered on campus. In the summer of 1999, a total of twentynine students registered in the first online version of the course, with twenty-eight students actually finishing this course. The majority of the students were from the College of Commerce and Business Administration, except the few who were majoring in engineering or computer science. Each of these students worked at a summer job. The 8-week course began on June 14, 1999 and ended on July 5, 1999.

The three primary tools in addition to standard email and Internet browsers for this class were Mallard, RealPlayer, and WebBoard (http://www.cet.uiuc.edu/selection.asp). Mallard is a password-protected webbased course management system developed at UIUC. In ECON 300, Mallard housed lecture videos, quizzes, and homework assignments. The students logged into Mallard to view lectures, take quizzes, download homework assignments, and to take exams. They could also check their grades on Mallard. The lecture videos, including Powerpoint lecture slides, were viewed using RealPlayer. WebBoard is a computer conferencing system that enables students and teaching staff to communicate online synchronously and asynchronously. For ECON 300, WebBoard was used for asynchronous class discussions, technical support, handing in homework assignments and communication between teaching staff and students and among students, which was either asynchronous or in a synchronous chat room.

As the ALN model would suggest, most of the ECON 300 course was conducted asynchronously with only exams, scheduled chat appointments or spontaneous chats taking place synchronously. On the class days, which were Mondays, Tuesdays and Thursdays, the instructor put online the lecture video that was taped and edited ahead of time. The students viewed the lecture and completed associated quizzes over the Internet within the next couple of days at their own schedule. The asynchronous class discussions were organized around the articles chosen from current editions of the Sunday New York Times Business section. On each Sunday, the instructor put online three articles along with discussion questions. The students were required to post an initial response to one of the three articles by the following Wednesday and to reply to at least one other students' initial posts by Saturday. In addition, the students worked in small groups of three to complete five problem sets during the semester. The group work was done over the Internet asynchronously through WebBoard conferencing, emails or through synchronous chats. The final grades were based on the quiz scores, participation in class discussions, completion of group-based problem sets, and scores on mid-term and final exams.

In the past, the instructor taught this course in a face-to-face setting on-campus with substantial technology components, using Mallard and FirstClass, which were replaced by WebBoard in the summer. Although the instructor was familiar with these technologies, it was his first time teaching students who 
were at a distance where there was no face-to-face component to the course. The students only met the instructor and the teaching assistants and each other face-to-face one time, at the end of Spring semester, in a meeting devoted to class administration and preparation. There were three undergraduate teaching assistants, who each took this course from the instructor before on-campus. Without a face-to-face component, all communications between the students and the teaching staff were through email and text chat. The instructor's office hours were all by appointment through email messages. The three teaching assistants took turns logging into the Chat Room in WebBoard during their office hours, which were from 7:00 or 8:00pm to 11:00pm every night, Monday through Thursday, plus Sunday from 4:00 to 8:00pm. The teaching assistants also served as graders for the problem sets.

\section{LITERATURE REVIEW}

Some common themes have emerged across the literature on learning experience and the effectiveness of online environments, such as learner satisfaction, learning outcomes, online communication, attitude toward technology, technological support, computer experience, prior participant knowledge, online learner skills, and gender differences. The present study explores each of these issues with regard to their applicability in a situation where on-campus undergraduate students become online distance learners for the summer. In the next section, we review the existing research in the areas of learner satisfaction and learning outcomes, the two indicators employed in the study, to look at how the students functioned in a distance learning environment where they were separated from their academic peers as well as working summer jobs. We also review the relevant literature in the areas of online learning environments, online learner skills, prior experience, and gender differences -- areas of possible explanation for observed variance in students' satisfaction and learning outcomes in this ALN course.

\section{A. Learner Satisfaction}

Learner satisfaction and learning outcomes are the two most commonly used indicators of course effectiveness, especially in the online learning studies [9]. Satisfaction relates to perceptions of being able to achieve success and feelings about the achieved outcomes [10]. Studies of learner satisfaction are typically limited to one-dimensional post-class assessments of learners' perceptions. Learner satisfaction often is measured with "happy sheets" that ask the learners to rate how satisfied they were with their overall learning experience. However, it is also meaningful to explore the notion of satisfaction through a multidimensional analysis of a wide variety of critical variables in order to provide effective measures that guide improvements in instructional design for online programs [11]. Therefore, some researchers have been trying to identify some critical variables in online learning. For instance, Jegede, Fraser, and Curtin [12] identified eight components of effective learning environments: interactivity, instructional support, task orientation, teacher support, negotiation, flexibility, technological support, and ergonomics. Similarly, some case studies focusing on the online students' perspectives propose a set of importance issues such as online communication, technical support, and course design [13][14][15].

Online interaction and communication have long been regarded as important factors for successful online learning [16][17][18]. Lack of communication is one of the most common frustrations in online learning [15][19]. In the current study, the students in ECON 300 were transformed from full-time, classroom students into distance learners who participated in class online from a distance and alone. Thus, their communication with the teaching staff and with fellow classmates, as well as their perceptions of the communications level was expected to be important to their learning.

With respect to the instructor's role in an ALN, technical support and course design have been cited as the primary responsibilities of the instructor in facilitating online learning. Mory et al.'s [13] case studies indicated the importance of technical support when students face technical problems, and found that even temporary outages of the technology supporting ALN had a negative impact on students and their learning outcomes. Similarly, Webster and Hackley [9] found course design to have a crucial influence on students' success in an online environment. 
Based on this literature, we have adopted a multidimensional notion of satisfaction in this study as indicators of course effectiveness. In addition to measuring learner satisfaction in the traditional fashion by asking the students how satisfied they were with their overall learning experience, we also assessed the students' perceptions of three important aspects of online learning. Specifically, the students reported their satisfaction with online communication, technical support and course design.

\section{B. Learning Outcomes}

Another very common measure of course effectiveness is student performance. Final grades in a class are always used as indicators of program quality and student learning [9]. In this study, we use the final scores as the indicator of the learning outcomes for each student.

\section{Online Learning Environments}

In traditional classrooms, learning occurs within physical boundaries - for example, a classroom, a school, and field trips, and various other locations [20]. By contrast, with ALN(s), learning can happen anywhere and anytime without the limit of physical location [1]. There has been a lot of research studying pedagogical aspects of "online learning environments" [21]. However, relatively little research addresses physical characteristics of the overall learning environment, such as learning areas and Internet connections. In this study, we specifically address the students' perceptions of the physical settings from which they connected to and used the ALN, and how that might influence their satisfaction and learning outcomes.

\section{Special Sets of Skills}

The ALN learning environment often is very different from traditional face-to-face classroom settings. Previous ALN research has identified individual characteristics that seem to describe a successful online student. For instance, Gibson [22] finds that it is critical for distance students to be focused, better time managers, and able to work both independently and as group members, depending on the delivery mode and location of the distance course. Other studies suggest that important characteristics for online students include strong self-motivation, self-discipline, independence, and assertiveness [UI Online program: http://www.online.uillinois.edu/index.html] [23][24].

The full-time students in ECON 300 were used to traditional, face-to-face instruction and to having peers available both in class and in their living situations. In the ALN version of ECON 300, they were transformed into distance learners who participated in class online from a distance and, moreover, alone. These changes probably required a different set of skills, the lack of which might pose barriers to their learning. Thus, we were interested in the degree to which these traditional students possess the special set of skills required in an ALN environment such as motivation, self-discipline and time-management, and their potential influence on the students' satisfaction and achievement levels.

\section{E. Prior Experience}

Smith's [25] Learning-How-To-Learn (LHTL) theory suggests that learners rely on a "bag of tricks" including prior learning strategies and tactics, as well as things that worked in other situations to make sense of a new environment. Eastmond's [26] study also indicates that prior learning experience, among other factors, is important for students to adjust to online learning.

Familiarity with the technologies used in the online course is especially important for students who take a course online. Al-Kodmany et al's [8] case study of using ALNs to teach one class to students on two different campuses found that without prior exposure to the technologies involved, the technologies used in the course became barriers to learning. One of their suggestions for online instruction is not to attempt teaching the technology and the course at the same time, rather, impose certain prerequisites on technologies that are used in the course or include a mini-course on the technologies that is not the part of the course itself.

Researchers have also argued that the successful implementation of any new technology depends on factors related to users' attitudes and opinions [27][28]. For instance, Webster and Hackley [9] studied the 
teaching effectiveness in technology-mediated distance learning and found a positive relationship between students' attitudes toward technology and their learning outcomes.

In addition, we propose that prior experience with online classes might be helpful when taking a new class in an online version, although little research has explicitly addressed this issue. Presently on-campus courses are moving fast to integrate computers and Internet technologies into the classroom, however, only a small portion of the content in traditional courses is actually presented online and there still exists substantial opportunity to interact face-to-face. As a result, traditional students typically have very little experience with online courses. In the present study, prior online class experience might play a critical role when students transfer from being on-campus full-time learners to becoming distance, online parttime learners in this study.

Therefore in this study, we examine these three types of prior experience, including prior experience with technologies, prior attitude toward technology, and prior online class experience.

\section{F. Gender Difference}

Gender difference may have an impact on experience with an ALN environment. It has been suggested that females are more technophobic [29], have more negative attitudes toward computers [30], and are less confident in their use of computers [31] than males when they enter universities. The conclusions drawn by several researchers are that by the time students enter the university, males are more familiar with computers than are females [32] [33]. Still other researchers speculate that females are also less comfortable with the way that computers are used at many universities [34]. However, Ory, Bullock and Burnaska [35] found no gender difference in the use of and attitudes toward ALN in a university setting. According to his study, both males and females made similar use of ALN, had similar (positive) attitudes about their "computer experience," and shared a common desire to take more courses using computers.

The different conclusions from the existing research call for further exploration. With this in mind, we also examined gender differences in learner satisfaction, learning outcomes, computer use and prior experience.

\section{METHODOLOGY}

Two surveys (pre- and post-) were administered to the summer students enrolled in ECON 300, one at the beginning and one at the end of the semester, via a Web-based form (see the Appendix). The pre-survey was posted on June 14, 1999, the first day of summer semester, and all students responded within one week. The pre-survey covered demographics, motivations for taking this course, and prior experience. The post-survey was posted on August 3, 1999, and all responses were submitted by August 6, the last day of the summer semester. The post-survey covered learner satisfaction, learning environment, and the additional set of learning skills expected to be important for successful online learning. To help ensure a set of comprehensive responses, the students were encouraged to take the surveys by giving them extra points for submitting surveys (even blank surveys).

\section{A. Learner Satisfaction}

As stated earlier, we adopted a multidimensional notion of learner satisfaction, including satisfaction with online communication, technical support, and course design as well as overall online learning satisfaction. Each satisfaction dimension was assessed with a set of 5-point Likert-scale items in an opinion survey. Items II-1, 2, and 3 in the Appendix addressed various aspects of the students' attitudes toward online communication, and the average of these items was taken as satisfaction with communication. Similarly, items II-4, 5, and 6 addressed the technical aspects of this course, and the average was taken as satisfaction with ALN technologies. Item II-8 was taken as an indication of satisfaction with course design, while the average of items II-9, II-10, and II-11 was taken as satisfaction with learning experience. The overall satisfaction was measured as the average of all these above items. For those negative questions, such as items II-1, II-3, II-5 and II-10, we reversed the score before calculating the average of categories. The raw un-reversed scores are presented in the Appendix. 


\section{B. Learning Outcomes}

The students' learning outcomes in this class were measured by the final scores. The final scores were obtained from: (i) performance on the Web Quizzes (240 points), (ii) performance on the problem sets (240 points), (iii) class participation (80 points), (iv) the "getting started" assignment (10 points), (v) the surveys (10 points), (vi) the midterm exam (100 points), and (vii) the final exam (160 points). The highest score possible was 840 points.

\section{Learning Environment}

To assess the physical setting of the online learning environment for the students, the post survey included two open-ended questions (item II-12 \& II-13). In these questions the students were asked to describe their learning environments whether at home, library, office, or elsewhere, as well as the type of Internet access that they used.

\section{Special Set of Skills}

The special sets of skills required for online learning considered in this study are motivation, selfdiscipline, and time management. In the survey, whether a student was motivated internally or externally was assessed through an open-ended question (item I-1). Self-discipline was measured with a 5-point Likert-scale item (item II-14). Time management was measured with a 5-point Likert-scale item (item II 15) and three supplemental open-ended questions (item II-16, II-17, \& II-18), which addressed the students' work load, course load, and the way that they allocated their time for ECON300.

\section{E. Prior Experience}

Prior Experience included prior experience with technologies, prior attitude toward technology, and prior online class experience. In this study, prior experience with technologies (item I-2) was assessed with a five-point scale survey that asked for the students' ratings of their frequency of use of nine different online communication technologies such as WebBoard and Mallard, before taking ECON 300. The average scores on these items were calculated to be the prior technology experience score. Similarly, attitude toward technology was assessed with six 5-point Likert-scale items (item I-3). The average rating on these items was taken as the prior technology attitude score for each student. For those negative questions, we reversed the score before calculating the average of categories while presenting the raw unreversed scores in the Appendix. Finally, prior online class experience was assessed with two open-ended questions (item I-4 \& I-5).

\section{F. Gender}

Gender was asked as a background question in I-6.

\section{RESULTS AND DISCUSSSION}

The results were based on 29 submissions in the pre-survey and 26 submissions in the post survey with 24 students submitting both the pre and post surveys. In this section we present and discuss the results of learner satisfaction, learning outcomes, online learning environment, special online learning skills, prior experiences and gender differences. Note that the tables in this section present the mean scores on the variables of interest. The mean responses to each component item are listed in the Appendix along with the corresponding question.

\section{A. Learner Satisfaction}

The results of students' overall satisfaction, satisfaction with online communication, technical aspects of the course, course design, and their satisfaction with the online learning experience are shown in Table 1. In general, the students' overall satisfaction toward the course was lukewarm (mean $=3.05$ out of 5). Moreover, the students were not particularly enthusiastic about online communication, technical support, and their online learning experiences, with mean satisfaction levels ranging from 2.60 to 3.11 . In contrast, the students did have a very positive response to the course design with mean of 4.31 . 
Table 1. Learner Satisfaction

\begin{tabular}{llll}
\hline & N & Mean & SD \\
\hline Overall Satisfaction & 26 & 3.05 & 0.46 \\
Online Communication & 26 & 2.60 & 0.77 \\
Technical Support & 26 & 3.11 & 0.80 \\
Course Design & 26 & 4.31 & 0.79 \\
Online Learning Satisfaction & 26 & 3.01 & 0.64 \\
\hline
\end{tabular}

Considering the individual items comprising of the overall communication, on one hand, the students reported that they did not have more communication with the instructor than in a traditional class (mean $=$ 2.23 on item II-2) and that they did not have a chance to know their classmates (mean $=3.69$ on item II3 ). On the other hand, lack of communication didn't seem to bother them very much. The students somewhat disagreed (mean $=2.73$ ) with the statement that "I was frustrated by sitting alone in front of a computer when taking the class" (item II-1). This contradiction can be explained by the instructor's efforts to prepare students with a realistic perspective about taking course online. During the only one face-to-face meeting at the end of the Spring semester, the instructor emphasized the "studying alone" situation. This probably decreased students' expectations for communication in this class. Equipped with such a perception, the students were better prepared for the online experience in that although they noticed the difference in communication, they tended not to be frustrated by less communication with classmates and instructor than in traditional classes.

In terms of the technical aspects of the course, again the responses to individual items were fairly neutral. There was a bit of variability around the central means of 3.07 and 3.67 when responding to questions about technical support (II-5 \& II-6), with standard deviation of 1.35 and 1.68. The students barely thought, "technical problems were barriers when taking this class." In addition, most of the students did not use technical support other than the teaching staff, and very few of them (3/26) sought help from family and friends when facing technical problems. This was consistent with their prior technology experience and positive attitude toward technologies as is stated later. Since they already had enough technical background and familiarity with the three primary tools-- Mallard, RealPlayer, WebBoard-used in the class before taking ECON 300, the students didn't need to learn the technologies and the content at the same time.

The students also were neutral in their responses to the online learning experience. A lukewarm attitude toward this class was found in the students' rating on their online learning satisfaction. They did not strongly agree on item II-9, "I believe that I have learned from this class in an online format as much as I could from a traditional format" (mean $=3.03$ ). Furthermore, when they were asked "if possible, I would prefer taking this course in a traditional, face-to-face format" (item II-10), their responses were relatively neutral (mean $=3.20$ ). This result might reflect the types of students who enroll in summer session and the relatively weak motivation for learning that we might expect in them, as discussed later. However the overwhelmingly neutral response might also suggest that the online version was implemented well enough so that the students did not mind being removed from campus, colleagues and instructors. Recall that these students are traditional university students who are used to face-to-face classes. During this summer session they were transformed into online distance students. Therefore, we would expect many of the students to still prefer traditional classes. However the students did not seem to show a strong preference for either an online or face-to-face format after completing the course. The students' positive response to course design supports this interpretation.

In spite of the lukewarm attitude toward many aspects of the online communication and learning, the students were very satisfied (mean $=4.30$ ) with the course design (item II-8). Course design is crucial for an online class, which can greatly help students remain disciplined. In an online class, students usually assume more responsibility for learning and for keeping up with the class than they do in a traditional, face-to-face class. A good instructional design can help the students keep up with assignments, quizzes, and projects at an even pace. The design for ECON 300 seems to have been a very successful one in this 
regard, helping the students remain disciplined as most distributed their work evenly throughout the week. One student specifically stated that the instructional design helped him saying, "it is easy to keep up [in] the class with the quizzes and assignments."

\section{B. Learning Outcomes}

Their final scores indicated the students' learning outcomes. As shown in Table 2, the distribution of the scores was normal with the lowest score of 567.80 and the highest score of 788.50 out of possible full score of 840.

Table 2. Grades

\begin{tabular}{lllll}
\hline $\mathrm{N}$ & Low & High & Mean & $\mathrm{SD}$ \\
\hline 26 & 567.80 & 788.50 & 736.83 & 57.59 \\
\hline
\end{tabular}

The students' opinions of online communication, and technical aspects of the course, shed some light on the students' learning outcomes in this course. As shown in Table 3, there were significant correlations between the students' satisfaction with the online communication, technical aspects and course design, and their grades. This indicated that those aspects of the course were closely related to students' achievement. However, no significant relationships were found either between the students' satisfaction with learning and their grades or between their overall satisfaction with this course and their grades.

\begin{tabular}{lll} 
Table 3. Correlations between Learner Satisfaction and Grades \\
\hline Online Learning Experiences/Grades & \multicolumn{2}{l}{ Grade } \\
\cline { 2 - 3 } & $\mathrm{R}$ & $\mathrm{P}$ \\
Overall Satisfaction & 0.466 & $0.016 *$ \\
Online Communication & 0.467 & $0.016 *$ \\
Technical Support & 0.425 & $0.030 *$ \\
Course Design & -0.405 & $0.040 *$ \\
Online Learning Satisfaction & 0.196 & 0.337 \\
\hline
\end{tabular}

* significant at .05 level

A significant correlation between the students' grades and their communication satisfaction showed that the students who reported more online communication with the teaching staff and their classmates tended to have higher grades. The result supports the claim that online communication is an important factor for successful online learning [16][17]. The positive relationship between the students' satisfaction with technical aspects of the course and their grades also indicates the importance of technical support for online learning in ALN. The students with higher satisfaction with technical aspects of the course had higher grades. However, the significant relationship between the students' satisfaction with course design and their grades was negative, which meant that the students who had a higher opinion about course design had lower grades than those who had lower satisfaction with the course design. This might be explained by the fact that the higher achieving students were more critical about the course design.

Besides some aspects of learner satisfaction, other factors including prior online class experience and course load both had statistically significant effects on learning outcomes, which are discussed later.

However, we have to be aware of the limitation of using grade points as the indicator of learning outcomes when we consider the results presented above. Some researchers have argued that distance learning studies "need to move beyond the limited perspective of class grade point averages as indicators of program quality and student learning" [36]. But few studies suggested and tested alternative tools for 
objective measurement of learning outcomes other than class grades. In future studies, we should explore alternative measures of learning outcomes.

\section{Learning Environment}

The results from the open-ended questions indicated that the students actually preferred their learning environment at home or at their office rather than in a regular classroom. Most students believed they had a quiet learning area with little or no distraction. In future research, potentially less satisfying environments, such as university dorms, should also be explored.

Although the students seemed to be satisfied with their study areas, their response to their Internet connections, which is crucial to online courses, varied from "terrible" and "slow" to "good" and "reliable." Almost half of students (12 out of 26) used AOL as their Internet service provider. A few (5) students used the University's connection and were satisfied with the quality. The rest used MSN, USSnet, Essex, or a local Internet provider. In general, students didn't complain that the quality of their Internet connection inhibited taking this class. This could be explained by the fact that the ECON 300 class did not have any synchronous instruction or class session. Otherwise, the Internet connection might have been a more crucial issue.

\section{Special Set of Skills for Online Learning 1. Motivation}

Motivation could deeply affect students' attitude toward the class and learning, especially in an online learning environment. There were four types of motives for taking ECON 300 in an online format that were observed in the responses to the open-ended question (I-1). For the vast majority of the students, the main reason for taking this course was "being able to take a required course while working on summer jobs" (22/29). Some students (4/29) regarded taking this course online as an "interesting and challenging" experience, while few students (2/29) took it because of the good reputation of the instructor. Finally, one student felt that taking a course over summer was easier.

The responses did not suggest that the students had a strong desire to learn the content of ECON 300 . Earning credit for them was the main reason for taking the course although a couple of students took it because they thought the online experience would be interesting and challenging. One possible explanation is that ECON 300 is a core course required of the business and economics majors as well as a course that fulfills the social science requirement for non-majors. Thus, the students may not have had strong intrinsic motivations for learning. Since online learning usually requires some extra learning skills, such as high self-discipline and strong internal motivation, lack of these abilities can result in frustration and failure in online learning.

It may be that the general motivation for taking the class is skewed due to the biased sample of students in summer school. Students who opt for the required course in the summer may not be typical of those who take it during the regular semesters, just as a student stated that taking a course over summer was easier. This may potentially cause a skewed student population. Both the students' weak motivation and the skewed student body in the summer course are important factors in understanding their lukewarm attitudes towards learning and the online version of the course.

\section{Self-discipline}

Self-discipline is regarded as one of the most important skills for online learners. However in ECON 300, we failed to find any significant relationships between students' self-discipline and their grades or their satisfaction with different aspects of the course.

In ECON 300, the students didn't feel it was difficult to maintain self-discipline with this online format (item II-12, mean = 2.73). However, it is difficult to determine that the discipline was internal (e.g. selfdiscipline) or in response to the structure of the class. As we discussed earlier, the students overwhelmingly agreed that the course design helped them kept up with the class. These results, taken together, suggest that online course design is especially important for self-discipline in summer school considering the students' weak motivation and the skewed student body in summer courses. 
However, we have to be cautious in interpreting the results because of the limited measurement of selfdiscipline. In this study, the question that was used to measure self-discipline was more about how difficult it was to remain disciplined instead of how self-disciplined they were. Unfortunately, there is not an established methodology for measuring self-discipline.

In addition to course design, the students' course load and workload might also be related to selfdiscipline, which will be analyzed in the following section.

\section{Time Management}

The results from item II-13 and the open-ended questions (items II-14, II-15 and II-16) indicated that transferring from full-time, on-campus students to part-time, off-campus learners changed the students' schedules and their time management. However, these changes did not necessarily cause their frustrations. Most of them actually enjoyed the flexible schedule brought by ALN-learning anywhere and anytime.

First, we found that all the students had a summer job. Most of the students worked more than 40 hours per week (21/26) while some of them worked less than 20 hours a week (5/26). The difference in job workload resulted in a significant difference in self-discipline as shown in Table 4. The group that worked about 40 hours or more in their summer jobs reported an easier time at maintaining self-discipline than the group that worked 20 hours less per week. One possible reason is that a higher workload may force a person to use their time more effectively, leading to more self-discipline than in those who have lighter workloads. Alternatively, those students willing to work 40 hours and take a class may be those with better time management skills to begin with.

Table 4. T-Test: Self-discipline - Workload

\begin{tabular}{llllll}
\hline Work Load & $\mathrm{N}$ & Self-Discipline & SD & $\mathrm{T}$ & $\mathrm{P}$ \\
\hline $\begin{array}{l}\text { About or more } \\
\text { than } 40\end{array}$ & 21 & 3.667 & 1.278 & 3.496 & $0.002 *$ \\
$\begin{array}{l}\text { hours/week } \\
\begin{array}{l}\text { Less than 20 } \\
\text { hours/week }\end{array}\end{array}$ & 5 & 1.600 & 0.548 & & \\
* & & & & \\
\hline significant at .05 level & & & &
\end{tabular}

In terms of course load, 21 out of 26 students only took ECON 300 while the rest 5 took courses in addition to ECON 300. A significant difference in self-discipline was also found between these two different course load groups (Table 5). However, the significant pattern was in the opposite direction of that between two different workload groups. The group with lighter course load tended to maintain selfdiscipline more easily than the group with heavier course load. Similarly, we found a significant difference in grades between them as shown in Table 6. The grades of the group that only took ECON 300 during the summer session were significantly higher than the other group that took more than one class. These results are understandable especially considering that those students also worked at summer jobs. Taking more than one course would consequently decrease the time and energy the students could spend in ECON 300, which could possibly result in a lower grade.

Table 5. T-Test: Grades - Course Load: One/More Than One Course

\begin{tabular}{lllllll}
\hline Course Load & $\mathrm{N}$ & Grades & SD & SEM & T & $\mathrm{p}$ \\
\hline One Course & 21 & 749.314 & 44.582 & 9.729 & 2.491 & $0.020 *$ \\
More than One & 5 & 684.380 & 80.830 & 36.149 & & \\
*significant at .05 level
\end{tabular}


Table 6. T-Test: Self-discipline - Course Load: One/More Than One Course

\begin{tabular}{lllllll}
\hline Course Load & $\mathrm{N}$ & Self-Discipline & SD & SEM & T & p \\
\hline One Course & 21 & 3.571 & 1.326 & 0.289 & 2.412 & $0.024 *$ \\
More than One & 5 & 2.000 & 2.000 & 0.548 & & \\
\hline
\end{tabular}

*significant at .05 level

The hours that the students spent on the class ranged from 4 to 20 hours a week, which reflect these students' situation as working full-time. Additionally, the allocation of time to the class differed. Most students distributed their class work evenly over the week, while a few $(2 / 26)$ of them concentrated on the class once or twice a week. Again, this result was closely related to the course design. The well-structured ALN version of ECON 300 facilitated students' managing their time on this course. We failed to find any group differences in their grades and satisfaction perhaps due to the small sample of these two groups (2 vs. 24). However, the work and course load as well as the ways of allocating time to the class might have influenced students' achievement, which should be looked at in future studies with larger samples.

\section{E. Prior Experiences}

\section{Prior experience with technologies}

The results of prior experience with technologies indicated that most students had enough technology background to take this course. The high frequency of using email (mean $=4.86)$ and the World Wide Web $(W W W)($ mean $=4.41)$ shown in the results indicated the students were comfortable with these two basic technologies used in this class. Although they hadn't used WebBoard (mean $=2.79$ ) and Mallard (mean $=3.24)$ as often as they had email and the WWW, they did have some experience on average with these two important tools before taking this online course.

\section{Prior Attitudes toward Technology}

In addition to enough prior experience with technologies, the students had a relatively positive attitude towards technologies. The average score on six 5-scale questions on attitude toward technologies was 3.78. The prior attitude toward technology was significantly related to students' satisfaction with technical aspects of the course $(r=0.415, \mathrm{p}=0.044)$. It makes sense that the students who had a more positive attitude toward technology tended to have higher satisfaction with technical aspects of the course.

\section{Prior Online Class Experience}

Prior online class experience is important when students face a learning environment that is different from the traditional, face-to-face classroom. The survey results supported this claim in that the students' prior online class experience made statistically significant differences in their grades. Three of the total 24 students, who submitted both surveys, had taken an online course before ECON 300. The average grade of these three students was significantly higher than that of the rest of class as shown in Table 7. The prior online class experience might have prepared those students better for this class on an online format both mentally and technologically, which significantly affected their grades. The results are consistent with the results of some previous studies [8].

Table 7. T-Test: Grades - Prior Online Class Experience: Had/Never Had Online Class

\begin{tabular}{lllllll}
\hline Online Class & $\mathrm{N}$ & Grades & SD & SEM & T & P \\
\hline Had & 3 & 774.567 & 12.215 & 7.052 & 2.586 & $0.026 *$ \\
Never Had & 21 & 745.538 & 40.011 & 8.731 & & \\
\hline
\end{tabular}

*significant at .05 level

However, we must be aware of the small sample, which our conclusion was based upon. In the future, a study with a larger sample is needed to validate the conclusion. Moreover, students who choose to take another online class know what they are getting into, and maybe self-selected to do better in an online environment. 


\section{F. Gender Difference}

In this study, we observed some effects of gender differences on online learning. Although there were no differences in the students' satisfaction with the course and their achievement based on gender (Table 8), there was a significant difference in the prior experience with technologies and prior attitude toward technologies between male and female student (Table 9).

Table 8. T-Test: Gender Difference in Grades and Overall Satisfaction

\begin{tabular}{lllllllllll}
\hline & \multicolumn{1}{l}{ Grades } & \multicolumn{1}{c}{ Overall Satisfaction } \\
\cline { 2 - 11 } Male & $\mathrm{N}$ & Mean & SD & $\mathrm{T}$ & $\mathrm{p}$ & $\mathrm{N}$ & Mean & SD & $\mathrm{T}$ & $\mathrm{P}$ \\
Female & 13 & 752.853 & 12.215 & 0.498 & 0.623 & 13 & 3.231 & 0.492 & 1.654 & 0.112 \\
\hline
\end{tabular}

Table 9. T-Test: Gender Differences in Prior Experience with \& Attitude toward Technologies

\begin{tabular}{lllllllllll}
\hline & \multicolumn{3}{c}{ Prior Tech. Experience } & \multicolumn{7}{c}{ Prior Tech. Attitude } \\
\cline { 2 - 11 } Male & $\mathrm{N}$ & Mean & SD & T & P & N & Mean & SD & T & p \\
Female & 16 & 3.068 & 0.589 & 2.905 & $0.008 * *$ & 16 & 4.041 & 0.559 & 2.723 & $0.011 *$ \\
\hline
\end{tabular}

*significant at .05 level $* *$ significant at .001 level

Among the 29 students who submitted the pre-survey, there were 16 males and 13 females. Male students had significantly more experience with technologies than female students had. Similarly, male students expressed a significantly more positive attitude toward technology than female students. The more positive attitude and greater experience with technologies could be one reason that male students had slightly, but non-significant, higher grades (mean $=752.85)$ than females (mean $=744.81$ ), and had nonsignificantly higher satisfaction (mean $=3.23$ ) with the class than females $($ mean $=2.94)$. These results were consistent with other researchers' findings [35] about the similarity in male and female's use of and attitude toward ALN.

\section{CONCLUSION}

In general, this study has provided us with useful information about applying ALN in a summer school course for traditional undergraduate students who are away from their home campus. It is becoming more important to understand how traditional students adapt to ALN, as more on-the-job and lifelong training requirements will have to be met in online environments. The use of ALN in summer school provides us with a unique opportunity to explore those students' reaction to learning online and find the ways to help them prepare for the changes. Some of the findings from this study are meaningful for designing and improving such online classes in the future.

First, we should notice the special aspects of an ALN course, such as online communication, technical support, and course design. The quality of these factors is closely related to the students' achievement. In this study, course design appears to be a key issue in helping the students maintain self-discipline when they were transferred from full-time, on-campus students to part-time distance learners. This transformation also requires other skills, such as strong motivation and good time management. Moreover, even a comfortable learning environment and stable Internet access are important factors to look consider when offering online summer schools courses.

Overall, experience seems to be related to online summer school satisfaction and achievement. The more experience traditional students have with online courses, the more likely they are to be comfortable with the format, technology and pace of future online courses. However, traditional students also can gain experience that is useful for success in online summer school courses through the integration of online features and technologies into traditional face-to-face classes. In addition, we should prepare students for taking online classes mentally and technologically in face-to-face sessions that describe the online 
learning experience and warn the students of potential problems they may encounter when trying to complete an online course. Thus the combination of enough prior experience with technologies and positive attitudes toward technology will better prepare traditional students for taking summer school courses online. Also, we should pay enough attention to gender difference to help female students prepare for and become more positive toward technologies and online instruction and learning.

One of the most common approaches used in evaluating online instruction is the media comparison study, an approach that focuses on, for example, comparing the learning outcomes of one group receiving the instructional content through online means with another group receiving the same instruction via more traditional face-to-face means. However, a recent article by Lockee, Burton, and Cross [37] maintains that the continued focus on media comparison studies distracts researchers and evaluators from more productive lines of inquiry. The authors cite inherent flaws that are present in many published comparative studies in the distance education literature, such as non-comparable student groups and the sole attribution of student success/failure to the delivery medium.

We view the present study as an attempt to move beyond the media comparison study by exploring student outcomes in multiple dimensions concentrating solely on the unique situation at hand--traditional undergraduates with an opportunity to complete a home campus summer school course through ALN. We recognize that these students are in a situation that is not easily comparable to their on-campus counterparts enrolled in a face-to-face class session at the home university, as the students in the ALN version of the course have had to learn how to be distance education students--an experience that is altogether different from the ease and familiarity of simply attending a class at the home campus. For instance it would be very difficult to control for taking the class while living at home, or for the asynchronous nature of the ALN version of the course, without compromising the actual design and delivery of the ALN course. Furthermore, like Lockee, et al. [37], we recognize that instructional success in distance education is due to multiple variables that can influence learning, and this study has been an attempt at trying to characterize some of those variables.

As a final word of caution, the findings of this study should be viewed as preliminary because of the small sample sizes (26 and 29). A study with larger samples is needed to validate the conclusions. Further research should also be conducted to explore the issues raised in this study such as the limitations of measuring variables like learning outcomes and self-discipline. Additionally, this is only a survey study. Applying different research designs in future studies--such as through case study or mixed method (including combining quantitative and qualitative measures) approaches--can provide us with a greater understanding about the application of ALN to undergraduate summer courses.

\section{REFERENCES}

1. Mayadas, F. Asynchronous learning networks: A Sloan foundation perspective. Journal of Asynchronous Learning Networks, 1(1), 1997.

2. Arvan, L., Ory, J. C., Bullock, C. D., Burnaska, K. K., and Hanson, M. The SCALE efficiency projects. Journal of Asynchronous Learning Networks, 2(2), 1998.

3. Bourne, J. R. Net-Learning: Strategies for on-campus and off-campus network-enabled learning. Journal of Asynchronous Learning Networks, 2(2), 1998.

4. Hiltz, S. R. Impacts of college level courses via asynchronous learning networks: Some Preliminary results. Journal of Asynchronous Learning Networks, 1(2), 1997.

5. Geffen, A. Organizational issues in ALN. ALN Magazine, 3(1), 1999.

6. Hawisher, G. E., and Pemberton, M. A. Writing across the curriculum encounters asynchronous learning networks or WAC meets up with ALN. Journal of Asynchronous Learning Networks, 1(1), 52-72, 1997.

7. Bourne, J. R., Brodersen, A. J., Campbell, J. O., Dawant, M. M, and Shiavi, R. G. A model for on-line learning networks in engineering education. Journal of Engineering Education, ASEE 85(2), 253-262, 1996. 
8. Al-Kodmany, K., George, R. V., Marks, A., and Skach, J. A case study of teaching an urban design course on two campuses simultaneously. Asynchronous Learning Networks Magazine, 3(1), 1999.

9. Webster, J., and Hackley, P. Teaching effectiveness in technology-mediated distance learning. The Academy of Management Journal, 40(6), 1282-1309, 1997.

10. Keller, J. Motivational design of instruction. In C. Reigeluth (Ed.), Instructional design theories and models: An overview of their current status (pp. 386-434). Hillsdale, NJ: Erlbaum, 1983.

11. Johnson, S. D., Aragon, S. R., Shaik, N., and Palma-Rivas, N. Comparative analysis of online vs. face-to-face instruction. Retrieved January 14, 2000 from the World Wide Web: http://www.outreach.uiuc.edu/hre/public/comparison.pdf, 1999.

12. Jegede, O. J., Fraser, B., and Curtin, D. F. The development and validation of a distance and open learning environment scale. Educational Technology Research \& Development, 43(1), 90-94, 1995.

13. Mory, E., Gambill, L., and Browning, J. B. Instruction on the Web: The online students' perspective. Presented in SITE 98: Society of Information Technology \& Teacher Education International Conference, Washington, DC, March, 1998.

14. Everett, D. R. Taking instruction online: The art of delivery. Presented in SITE 98: Society of Information Technology \& Teacher Education International Conference, Washington, DC, 1998.

15. Hara N., and Kling, R. Students' frustrations with a web-based distance education course: A taboo topic in the discourse. Retrieved January 14, 2000 from the World Wide Web: http://www.slis.indiana.edu/CSI/wp99_01.html, 1999.

16. Sims, R. Interactivity: A forgotten art? Computers in Human Behavior, 13(2), 157-180, 1997.

17. Wegerif, R. The social dimension of asynchronous learning networks. Journal of Asynchronous Learning Networks, 2(1), 1998.

18. Haythornthwaite, C. Collaborative work networks among distributed learners. Proceedings of the 32nd Hawaii International Conference on System Sciences. Jan., 1999.

19. Saunders, N., Malm, L. D., Malone, B. G., Nay, F. W., Oliver, B. E., and Thompson, J. C. Jr. Student perspectives: Responses to Internet opportunities in a distance learning environment. Presented at the Annual Meeting of the mid-Western Educational Research Association, Chicago, IL, October, 1997.

20. Relan, A., and Gillani, B. B. Web-based instruction and the traditional classroom: similarities and differences. In B. H. Khan (Ed.) Web-Based instruction (pp.41-46). Englewood Cliffs, NY: Educational Technology Publications, 1997.

21. Hill, J. R. Distance learning environments via the World Wide Web. In B. H. Khan (Ed.) WebBased instruction (pp.75-80). Englewood Cliffs, NY: Educational Technology Publications, 1997.

22. Gibson, C. Toward an understanding of self-concept in distance education. American Journal of Distance Education, 10(1), 23-36, 1996.

23. Hardy, D. W., and Boaz, M. H. Learner development: Beyond the technology. New directions for teaching and learning, 71, 41-48, 1997.

24. Baker, M. H. Tips for being a successful distance student. Handout distributed at post-conference workshop, 11th Annual Conference on Distance Teaching and Learning, Madison, WI, August, 1995.

25. Smith, R. M. Learning how to learn. Chicago: Follett, 1982.

26. Eastmond, D. V. Alone but together: Adult distance study through computer conferencing. New York: Basic Books, 1995.

27. Davis, F. D., Bagozzi, R. P., and Warshaw, P. R. User acceptance of computer technology: A comparison of two theoretical models. Management Science, 35, 98-1003, 1989.

28. Zoltan, E., and Chapanis, A. What do professional persons think about computers. Behavior and Information Technology, 1, 55-68, 1982.

29. Karma, I. Setting up your own network. Green Teacher, 37, 26-38, 1994. 
30. Dambrot, F. H. The correlates of sex differences in attitudes toward an involvement with computers. Journal of Vocational Behavior, 27(1), 71-86, 1995.

31. Culley, O. Option choice and career guidance: Gender and computing in secondary schools. British Journal of Guidance and Counseling, 16(1), 73-82, 1998.

32. Gutek, B. A., and Bikson, T. K. Differential experiences of men and women in computerized offices. Sex Roles, 13(3), 123-136, 1995.

33. Neuman, D. Naturalistic inquiry and the Perseus project. Computers and Humanity, 25(4), 239-246, 1991.

34. Merrill, M. D. Constructivism and instructional design. Educational Technology, 31(5), 45-53, 1991.

35. Ory, J. C., Bullock, C., and Burnaska, K. Gender similarity in the use of and attitudes about ALN in a university setting. Journal of Asynchronous Learning Networks, 1(1), 1997.

36. Cleveland, P. L., and Bailey, E. K. Organizing for distance education. In J. F. Nunamaker, Jr. \& R. H. Sprague, JR. (Eds.), Proceedings of the Twenty-seventh Annual Hawaii International Conference on System Sciences, 4, 134-141. Los Alamitos, CA: IEEE Computer Society Press, 1994.

37. Lockee, B., Burton, J. K., and Cross, L. H. No comparison: Distance education finds a new use for "no significant difference". ETR\&D, 47(3), 33-42, 1999

\section{APPENDIX: RESULTS OF THE SURVEYS}

Pre-Survey (29 submissions) 1 :

http://www.ncsa.uiuc.edu/edu/trg/econsurvey/

Post-Survey (26 submissions)2:

Learner Satisfaction

http://www.ncsa.uiuc.edu/edu/trg/econsurvey2/

For each statement, please fill the ONE response that indicates the extent to which you agree or disagree with the statement. The scale ranges from $1=$ STRONGLY DISAGREE to $5=$ STRONGLY AGREE.

$\begin{array}{lllll}1 & 2 & 3 & 4 & 5 \\ \text { Strongly } & \text { Somewhat } & \text { Neutral } & \text { Somewhat } & \text { Strongly } \\ \text { Disagree } & \text { Disagree } & & \text { Agree } & \text { Agree }\end{array}$

\section{Online Communication}

II-1 I was frustrated by sitting alone in front of a computer when taking the class.

Mean $=2.73 \mathrm{SD}=1.28$

II-2 I had more communication with the instructor compared to in traditional, face- to-face classes.

Mean $=2.23 \mathrm{SD}=1.24$

II-3 I didn't have enough chances to know my classmates well.

Mean $=3.69 \mathrm{SD}=1.19$

Technical Support

1 Items start with I-.

2 Items start with II-. 
II-4 Working with classmates and instructors through online technologies provided exciting experiences.

$$
\text { Mean }=3.15 \mathrm{SD}=.92
$$

II-5 Technical problems were barriers when taking this class*.

$$
\text { Mean }=3.07 \mathrm{SD}=1.35
$$

II-6 The teaching staff provided enough technical and learning support.

Mean $=3.27 \mathrm{SD}=1.08$

II-7 Open-ended Question:

Besides the online instruction staff, have you found other technical support? If so, who has helped you to fix technical problems?

Most students' answers were "NO”. Several said their family helped them.

\section{Course Design}

II-8 The instruction (lectures, homework, quiz \& projects etc.) was well designed for students to keep up with the schedule.

$$
\text { Mean }=4.31 \mathrm{SD}=.79
$$

\section{Online Learning}

II-9 I believe I have learned from this class in an online format as much as I could from a traditional format.

$$
\text { Mean }=3.03 \mathrm{SD}=1.08
$$

II-10 If possible, I would prefer taking this course in a traditional, face-to-face format.

Mean $=3.23 \mathrm{SD}=.82$

II-11 Overall, I was satisfied with this class and would recommend it in the online format to my friends. Mean $=3.23 \mathrm{SD}=.81$

\section{Learning Environment}

II-12 Where do you take this class online (classroom, computer lab, dorm, house/apartment, or office)? How would you describe your learning environment (quiet, some distraction etc.)?

II-13 Which Internet service provider do you connect to when taking this class (UIUC, AOL, Netzero etc.)? How would you describe your Internet connection (fast/slow, stable, reliable etc)?

Special Set of Skills for Online Learning

Motivation

Open-ended Questions

I-1 Please indicate the main reasons why you take this class in on-line format without Face to face components?

-- To be able take required course while working on summer job

-- Easier over summer 
-- Interesting and challenging by taking class online 4

-- Good reputation of the instructor

Self-discipline

II-14 It was difficult to keep self-discipline in learning with this online format. Mean $=2.73 \mathrm{SD}=1.43$

Time Management

II-15 I spent more time on this class compared to on a traditional, face-to-face class. Mean $=3.23 \mathrm{SD}=1.24$

Open-ended Questions:

II-16 Is this the only class you are taking in the summer? If not, how many other classes are you taking?

Took more than one course besides ECON $300 \quad 5$

Only took ECON 300

II-17 Are you working in the summer? If yes, how many hours per week do you commit to that job?

Worked less or about 20 hours a week $\quad 5$

Worked about 35-40 hours a week 21

II-18 How many hours per week do you spend on this class? How do you schedule the time (regular hours everyday, or once or twice a week)?

About or less than 10 hours a week 10

More than 10 hours up to 20 hours a week $\quad 16$

Prior Experience

Prior Experience with Technologies

I-2. For each technology listed below, please fill the ONE response that indicates the frequency with which you used them before taking this class. The scale ranges from $1=$ NEVER to $5=$ DAILY.

$\begin{array}{lllll}1 & 2 & 3 & 4 & 5 \\ \text { Never } & \text { Few times } & \text { Monthly } & \text { Weekly } & \text { Daily } \\ & & & \\ \text { Email } & \text { Mean }=4.86 & \text { SD }=.35 & \\ \text { WWW } & \text { Mean }=4.41 & \text { SD }=.57 & \\ \text { Newsgroups } & \text { Mean }=2.56 & \text { SD }=1.10 \\ \text { Hypernews } & \text { Mean }=2.13 & \text { SD }=.35 \\ \text { Text chat only } & \text { Mean }=2.28 & \text { SD }=1.07 \\ \text { Audio chat } & \text { Mean }=1.24 & \text { SD }=.51 \\ \text { RealPlayer } & \text { Mean }=2.34 & \text { SD }=1.32 \\ \text { WebBoard } & \text { Mean }=2.79 & \text { SD }=1.74 \\ \text { Mallard } & \text { Mean }=3.24 & \text { SD }=1.50\end{array}$




\section{Prior Attitude toward Technology}

I-3. For each statement, please fill the ONE response that indicates the extent to which you agree or disagree with the statement. The scale ranges from $1=$ STRONGLY DISAGREE to 5 = STRONGLY AGREE.

$\begin{array}{lllll}1 & 2 & 3 & 4 & 5 \\ \text { Strongly } & \text { Somewhat } & \text { Neutral } & \text { Somewhat } & \text { Strongly } \\ \text { Disagree } & \text { Disagree } & & \text { Agree } & \text { Agree }\end{array}$

I always want to try new technologies.

$$
\text { Mean }=4.03 \mathrm{SD}=1.01
$$

I enjoy the convenience that technologies give me.

$$
\text { Mean }=4.41 \mathrm{SD}=.56
$$

I don't like new technologies, even though I do use them*.

Mean $=1.72 \mathrm{SD}=.92$

I am optimistic about the way technologies are changing the world and my life.

Mean $=4.17 \mathrm{SD}=.89$

I am slow to catch on how to use new technologies*.

$$
\text { Mean }=2.66 \mathrm{SD}=1.20
$$

I am one of the most technically-savvy people I know compared to my colleagues.

$$
\text { Mean }=2.48 \mathrm{SD}=1.09
$$

\section{Prior Online Class Experience}

I-4. Have you participated in any on-line classes before?

Yes 3

No 26

I-5. If your answer is "yes," please specify your experiences (as an on-line or onsite student, what do you think about this kind of experience).

-- online Latin American History

-- two Spanish Classes in which Mallard and FirstClass were used. Also took Econ class in which Mallard was used.

Gender

I-6 Pre-survey Post-survey

Male $16 \quad 15$

Female 13

\section{ABOUT THE AUTHORS}

Lanny Arvan directs the Sloan Center for Asynchronous Learning Environments (SCALE). SCALE was established in 1995 with a grant from the Alfred P. Sloan Foundation. Faculty members 
involved in the Sloan Center are participating in a three-year project of restructuring undergraduate courses to integrate into these courses various techniques associated with asynchronous learning networks (ALN). These ALN techniques include network-based access both to learning materials (e.g., multimedia tutorials, information on the world wide web) and to people (via asynchronous conferencing systems, such as PacerForum and FirstClass).

X. Christine Wang, Alaina Kanfer and D. Michelle Hinn also work with the National Center for Supercomputing Applications at the University of Illinois at Urbana-Champaign: http://www.ncsa.uiuc.edu.

$\mathrm{X}$. Christine Wang is a doctoral student in early childhood education at the University of Illinois at Urbana-Champaign. She participated in several online educational technology projects while working as a research assistant with the Technology Research Group at NCSA from 1998 to 2000. Currently, she is conducting her doctoral dissertation study on using computer/Internet technologies to foster and facilitate children's collaborative learning.

D. Michelle Hinn is a Ph.D candidate in Educational Psychology at the University of Illinois at UrbanaChampaign where she is a research assistant for both the National Center for Supercomputing Applications (NCSA) and the Office of Instructional Research. Her current research involves the design and evaluation of immersive virtual reality edutainment environments. Additionally, she has been involved in projects that have focused on the evaluation of information technologies, disability

accessibility for web-based learning environments, scenario-based web design, and the use of audio in multimedia educational applications. She is also an associate editor for the International Journal of Educational Technology, http://www.outreach.uiuc.edu/ijet. 